In Memoriam

\title{
DOS HITOS EN EL CAMINO HACIA UNA CONCEPCIÓN DEMOCRÁTICA Y HUMANISTA DEL ISLAM: MOHAMMED ARKOUN Y NASR HAMID ABU ZAYD
}

\author{
MOHAMMED ARKOUN AND NASR HAMID ABU ZAYD: \\ TWO MILESTONES IN THE PATH FOR A DEMOCRATIC AND \\ HUMANIST NOTION OF ISLAM
}

José Cepedello Boiso

Universidad Pablo de Olavide de Sevilla

Recibido: febrero de 2011.

E.mail: jcepboi@upo.es

Palabras clave: crítica del discurso religioso, hermenéutica jurídica, reformismo islámico, Mohammed Arkoun, Nasr Hamid Abu Zayd

Keywords: criticism of religious discourse, Islamic reformism, legal hermeneutics, Mohammed Arkoun, Nasr Hamid Abu Zayd

Resumen: En el presente texto, se muestran los datos biográficos más relevantes de la vida de los pensadores Mohammed Arkoun (19282010) y Nasr Hamid Abu Zayd (1943-2010), así como los aspectos esenciales de su moderna comprensión de la hermenéutica coránica, como elemento imprescindible para alcanzar una concepción democrática y humanista del Islam. Ambos autores coinciden en la necesidad de renovar las técnicas exegéticas de interpretación de los textos sagrados en el Islam (el Corán y la Sunna) como mecanismo teórico imprescindible para poder superar las concepciones cerradas y autoritarias que, durante siglos, fueron muy relevantes en los sistemas jurídicopolíticos de raíz islámica. En su opinión, la defensa de una lectura abierta de los textos sagrados es una tarea imprescindible que permitirá, por un lado, recuperar el carácter emancipador y humanista del mensaje islámico originario $y$, por otro, establecer un modelo jurídicopolítico más acorde con los valores democráticos de la modernidad.

Abstract: In this work we discuss the most relevant aspects of the biographies of the Islamic thinkers Mohammed Arkoun (1928-2010) and Nasr Hamid Abu Zayd (1943-2010), together with the key points 
of their modern interpretation of Quranic hermeneutics, taken as an indispensable element to achieve a humanist and democratic notion of Islam. Both authors agree on the need to renew the exegetic techniques about Islam's Holy Texts interpretation (Qu'ran and Sunnah) as a necessary theoretical tool to overcome the closed and authoritarian ideas that were for ages the cornerstone of many Islamic-rooted legalpolitical systems. In their opinion, to defend an open reading of Holy Texts is an unavoidable task that will allow, on the one hand, to recover the humanist and emancipatory character of the original Islamic message, and in the other hand, to establish a legal-political model more suitable for the democratic values of the modern era.

Mohammed Arkoun (1928-2010), profesor de origen argelino en la Universidad de la Sorbona, y Nasr Hamid Abu Zayd (1943-2010), pensador egipcio que tuvo que refugiarse en los Países Bajos tras ser condenado en su país por apostasía, han sido dos de los pensadores islámicos contemporáneos que, con más intensidad, han intentado desvincularse de las interpretaciones dogmáticas de los principios jurídico-políticos del Islam. A lo largo de su extensa y dilatada obra, ambos defienden que el sustrato último de las concepciones hermenéuticas que desembocan en una exégesis cerrada e inamovible de los textos sagrados no se halla en una supuesta necesidad de mantener intacto el sentido original de los escritos islámicos fundacionales, sino en la búsqueda de unos principios religiosos inmutables que sirvieran como legitimación para las variadas estructuras jurídico-políticas de carácter autocrático que, tras la impronta llevada a cabo por las técnicas hermenéuticas impuestas por las dinastías omeya y abasida, se han sucedido, a lo largo de los siglos, por todo el orbe islámico. En consecuencia, tanto Arkoun como Abu Zayd, conside- ran que el avance hacia formas de organización jurídico-políticas de base democrática, en el mundo islámico, sólo será posible si se recupera el espíritu humanista original de este credo y se realiza la tarea previa de desmontar o deconstruir las interpretaciones ortodoxas autoritarias de los textos sagrados, al mismo tiempo que se desarrollan renovadas técnicas exegéticas que permitan reconstruir una concepción democrática y emancipadora del Islam.

\section{Mohammed Arkoun (1928-2010)}

Mohammed Arkoun nació en Argelia, en 1928, en la aldea bereber de TaourirtMimoun, perteneciente a la provincia (wilaya) de Tizi Ouzou, situada en la región de la Gran o Alta Cabilia, cerca de la costa mediterránea, al este de la capital, Argel. Realizó los cursos correspondientes a la enseñanza primaria en su villa natal y los de secundaria en la ciudad de Orán. Comenzó sus estudios universitarios en la Facultad de Letras de la Universidad de Argel, trasladán- 
dose posteriormente a la Universidad de la Sorbona en París, en la que fue lector de lengua árabe desde 1956 y en la que se doctoró en Filosofía en 1968. Consolidó su reputación académica, durante los años siguientes, con sus investigaciones sobre la obra del filósofo Ibn Miskawayh en su etapa de profesor en la Universidad de Lyon 2, hasta alcanzar, en 1972, la plaza de profesor de pensamiento islámico en la Universidad de la Sorbona, en la que enseñó durante veinte años (1972-1992), hasta retirarse como profesor emérito. Además de su labor docente en suelo francés, ha sido profesor visitante en numerosas universidades de todo el mundo como UCLA (1969), Louvain-la-Neuve (19771979), Berlín (1986-1990), Princeton (1992-1993) y Amsterdam (1991-1993). Como editor y director científico de la revista Arabica (Brill, Leiden) desempeñó un papel esencial en el desarrollo de los estudios occidentales sobre la doctrina islámica, a los que contribuyó, por su parte, con un ingente número de artículos publicados en una gran variedad de publicaciones académicas. Es autor, además, de numerosos libros en francés, en inglés y en árabe, de entre los que podemos destacar: Le Coran (1970), La pensée árabe (1979), L'Islam, religión et société (1982), Pour une critique de la raison islamique (1984), Essais sur la pensée islamique (1984), Rethinking Islam (1994), The Unthought in Contemporary Islamic Thought (2002) o De Manhattan à Bagdad. Au-delà du Bien et du Mal (2003). Entre otras distinciones recibió del gobierno francés la Legión de Honor en 1996 y el Premio Giorgio Levi della Vida, otorgado en 2001 por la Universidad de California-Los Ángeles, por su decisiva contribución al desarrollo de los estudios islámicos en Occidente. Vivió sus últimos años en París, como profesor emérito, siendo también Investigador Senior y miembro del equipo de gobierno del Instituto de Estudios Ismailíes en Londres, hasta su muerte, el 14 de septiembre de 2010.

Desde un punto de vista teórico, Mohammed Arkoun dedicó gran parte de su labor de indagación intelectual a la doble tarea de, por un lado, desvincular el Islam de las interpretaciones dogmáticas y, por otro, desarrollar una nueva concepción de la doctrina islámica más acorde tanto con su espíritu original, como con conceptos jurídico-políticos esenciales en el mundo contemporáneo como la democracia y los derechos humanos $^{1}$. La finalidad principal de su obra es, en este sentido, desmontar la visión tradicional del Islam, que durante siglos había sido utilizada como modelo religioso de legitimación de un gran número de sistemas jurídico-políticos de carácter autocrático y que, a lo largo del siglo XX, había sido revitalizada por los autores más relevantes del fundamentalismo islámico. Esta labor es la que Arkoun denomina crítica de la razón islámica clásica o dogmática y, para la cual, propone la necesidad de superar los principios de la islamología clásica, con la finalidad de construir una moderna islamología aplicada, mediante el desarrollo de las herramientas teóricas de análisis, tanto de los textos sagrados y sus interpretaciones canónicas como de la realidad actual de las sociedades musulmanas, imprescindibles para alcanzar una concepción más adecuada 
del Islam contemporáneo. A través de la crítica de la razón islámica dogmática, la islamología aplicada tendría como uno de sus objetivos esenciales demostrar que no existe contradicción ontológica alguna entre este credo y la defensa de valores modernos como la democracia o los derechos humanos, sino que, muy al contrario, el Islam posee, desde sus orígenes, un componente humanista que le hace perfectamente compatible con ellos y que le permite, incluso, aportar aspectos relevantes para un desarrollo más acertado de los mismos, completando algunas deficiencias manifestadas por las estructuras jurídico-políticas occidentales.

Sobre la base de esta necesaria renovación metodológica, Arkoun se propone la necesaria tarea de repensar el Islam, mediante un estudio sistemático y minucioso de las herramientas hermenéuticas más apropiadas para la determinación de los procedimientos exegéticos más idóneos de interpretación de sus textos sagrados: el Corán y la Sunna. De forma acorde con Abu Zayd², y en línea con los planteamientos hermenéuticos de Duby, Le Goff, Foucault y Derrida, defiende que, con tal fin, es imprescindible desarrollar un proceso de deconstrucción de lo impensado y lo impensable en el pensamiento islámico clásico y contemporáneo, para conseguir liberar el credo islámico de los angostos confines definidos por las visiones del tradicionalismo ortodoxo ${ }^{3}$. El objetivo esencial de su indagación es, por tanto, la puesta en práctica de una nueva iytihad, que permita una radical reconstrucción del significado de los textos sagrados, sacando a la luz todo aquello que, al mantenerse oculto o impensado, impedía el acceso a nuevas formas de lo pensable, obstaculizando la necesaria renovación de una concepción de la realidad que permanecía amarrada, de forma anacrónica, a las coordenadas históricas medievales. La nueva hermenéutica coránica exige dilucidar todos los problemas lingüísticos, semióticos, históricos y antropológicos que entrañan el Corán y la Sunna como textos, esto es, como sistemas de signos, susceptibles de ser interpretados de una manera abierta, sin que este hecho suponga, necesariamente, una traición a su sentido original. En palabras de Arkoun, toda esta labor supone, de forma inevitable, «una radical reconstrucción de la mente y la sociedad en el mundo musulmán contemporáneo» ${ }^{4}$.

Arkoun define el texto coránico como un corpus finito y abierto de enunciados en lengua árabe a los que sólo se puede acceder a través del texto fijado desde el siglo IV/X $X^{5}$. En tanto que totalidad, el rasgo más característico del Corán es que ha funcionado simultáneamente como una obra escrita y como palabra litúrgica sagrada. Su carácter sagrado le ha conferido un valor performativo de singular relevancia, en la medida en que se ha constituido como el texto delimitador de la vida islámica en todos sus órdenes: religioso, moral, personal, social, político, económico, militar, jurídico o artístico. Esta especial consideración del texto coránico le confiere una inigualable capacidad para desplegar, en el ámbito de las relaciones socio-políticas, la estructura designativa configurada en el mismo. Debido a su capacidad para determinar la acción individual 
y social en todos sus niveles, la palabra escrita se presenta como el principal elemento de control político en el seno de las sociedades islámicas, hasta el extremo que, según los planteamientos de autores fundamentalistas contemporáneos como Maududi o Qutb, la delimitación absoluta de la vida social debe constituirse como un mero despliegue fáctico del contenido significativo enunciado tanto en las Suras del Corán como en los Hadices que, junto a la Sira, conforman la Sunna.

En consecuencia, la delimitación correcta del contenido de los textos sagrados es un hecho de singular relevancia dentro de este credo religioso, por lo que, desde los primeros tiempos, la cultura islámica prestó una singular atención a todos los problemas relativos a la hermenéutica textual. La precisa interpretación del texto coránico no es un hecho que afecte, tan sólo, a la búsqueda de un alto grado de exactitud, a la hora de determinar un contenido referencial o significativo meramente constatativo, sino que está orientada, desde su origen mismo, a la delimitación de los modelos y manifestaciones aceptables en el comportamiento tanto individual como social. Las herramientas interpretativas adquieren, de esta forma, una singular relevancia, desde el punto de vista político y jurídico, ya que se configuran como los elementos necesarios de intermediación entre el texto y las modalidades de acción individual y social. En otras palabras, en el seno de las sociedades de raíz islámica, el texto sagrado y su exégesis se constituyen como las fuentes últimas de la legitimidad jurídico-política.
Arkoun considera, por tanto, que, en toda indagación acerca de la configuración de las estructuras jurídico-políticas en las sociedades islámicas, es imprescindible partir del acentuado carácter performativo concedido a la palabra en este credo. El lenguaje se configura como el elemento de transformación radical de la realidad, en todos sus órdenes y, de ahí, la importancia otorgada a la determinación de los métodos de interpretación textual y discursiva. En estas coordenadas, el control del texto y de los mecanismos hermenéuticos otorga a quien lo ejerce una capacidad de actuación política inigualable en el mundo musulmán, por lo que es imposible indagar en las raíces últimas de la política y del derecho islámicos sin resolver de antemano el gran cúmulo de cuestiones referentes a las circunstancias de todo tipo que rodearon la determinación del considerado como auténtico texto sagrado, así como el desarrollo y consolidación de las técnicas de exégesis del mismo. El estudio de este tema muestra bien a las claras que el texto ortodoxo fue fruto de una serie de decisiones esencialmente políticas. La Vulgata oficial, que se fue imponiendo a partir del Califato de Uthman (644-656), acabó configurándose, con el paso de los años, como una versión impuesta por los sucesivos califas omeyas y abasidas. En este proceso de depuración del texto, se fueron acumulando fenómenos característicos de toda de transmisión textual como las diversas destrucciones de corpus anteriores, la eliminación de versiones como la de Ibn Mas'ud e incluso dificultades con la grafía árabe a la hora de reproducir ciertos fragmentos. En 
consecuencia, a pesar de que corrientes contemporáneas como el fundamentalismo intentan soslayar toda la problemática referente a las condiciones de surgimiento del texto sagrado, con la intención de facilitar la penetración de una determinada e interesada impronta ideológica en los procedimientos performativos asignados al mismo, es indudable que la forma definitiva transmitida fue fruto de una serie de decisiones políticas que condicionaron sobremanera el contenido lingüístico específico consolidado como palabra divina ${ }^{6}$. Las clases dirigentes buscaron, desde siempre, en la autoridad trascendente del Corán, un principio de legitimidad política que consolidara los modelos de gobierno más favorables para sus intereses y que permitiera la perpetuación de su poder. Por lo tanto, una lectura crítica actual del texto coránico no debe ser tan sólo un ejercicio hermenéutico formal, sino un minucioso proceso de análisis que descubra los mecanismos que permiten que una concepción religiosa y cultural sea configurada por las ideologías políticas dominantes en cada momento ${ }^{7}$.

La reconsideración exegética de los textos sagrados exige distinguir entre tres momentos que los métodos hermenéuticos ortodoxos identifican, con la intención de legitimarse como doctrina única. Estos tres momentos son: a) el acto discursivo original del Profeta; b) el corpus oficial cerrado o Mustaf; y c) la imposición de la exégesis oficial o dogmática. En relación con el primer aspecto, hay que señalar que el acto oral original fue realizado en una lengua, en un concreto género discursivo y en un len- guaje simbólico y mítico, adaptado a la específica situación histórica en que se llevó a cabo, mientras que la tradición exegética supone una apropiación de una concretización determinada de ese acto de locución oral, el texto oficial, realizada por las distintas facciones de la comunidad musulmana, a lo largo de diversos contextos históricos que divergen, en aspectos esenciales, tanto del momento del acto de habla original, como del contexto de consolidación del texto oficial. Entre la palabra del Profeta y su comprensión contemporánea hay, pues, dos elementos de mediación que las doctrinas fundamentalistas intentan obviar: la determinación del corpus oficial y las sucesivas pugnas exegéticas por controlar la correcta interpretación del texto coránico, que acaban desembocando en una supuesta interpretación auténtica y única. Esto supone dejar de lado, de forma interesada, la relación dialéctica inevitable que se produce entre el texto revelado y la historia, con la finalidad de presentar el Corán como un texto cerrado que sólo ofrece una visión inmutable del mundo y, en consecuencia, un modelo jurídico-político único e irrenunciable para el auténtico creyente, sustentado sobre la base de la sharía. En opinión de Arkoun, la búsqueda de compatibilidad entre la modernidad y las fuentes del credo islámico exige entender el Corán como un texto abierto que posee, en potencia, un infinito abanico de posibilidades interpretativas, mediatizadas todas ellas, de forma inevitable, por las circunstancias de cada época y por los métodos intelectuales característicos de los momentos históricos en que se desarrollan. Es, pues, necesario 
que los intérpretes actuales utilicen los instrumentos de la semiótica histórica y de la sociolingüística para distinguir entre las interpretaciones particulares tradicionales y el significado que el texto coránico puede adquirir, no para un lector medieval, sino para un lector de nuestro tiempo. Con esta finalidad, es preciso, en primer lugar, descubrir y sacar a la luz los mecanismos de producción de sentido utilizados por los métodos clásicos de exégesis para, posteriormente, desarrollar las herramientas hermenéuticas que permitan la creación de sentidos diferentes, más acordes tanto con el espíritu original de la locución oral del Profeta como con las circunstancias del mundo contemporáneo.

El cumplimiento de esta práctica de renovación conlleva la exigencia de abandonar las interpretaciones dogmáticas, surgidas por el error hermenéutico de conceder un sentido cerrado y unívoco a los textos sagrados, y desarrollar, como alternativa, una nueva deuda de sentido que no parta de un único modelo de referencia, sino que aproveche los valores de emancipación presentes en la variada diversidad de corrientes e influjos intelectuales, tanto internos como externos, que constituyen la modernidad islámica. Arkoun reconoce que esta tarea es indudablemente ardua, ya que es inmenso, en todos los sentidos, el poder de los dos grandes polos que intentan monopolizar el pensamiento y la acción de la comunidad islámica y que, utilizando la terminología de Benjamín R. Barber, pueden identificarse, de forma simbólica, como el enfrentamiento entre Yihad y McWorld. ${ }^{8}$ Estas dos estructuras de poder, que representan al integrismo islámico, por un lado, y a las fuerzas de la libre economía de mercado, por otro, utilizan toda su capacidad propagandística para orientar, de manera específica, la forma como los sujetos otorgan sentido a todos los aspectos de la realidad, creando, en consecuencia, una doble deuda de sentido basada en la oposición y, por tanto, tendente al enfrentamiento y al desarrollo de políticas sustentadas en la confrontación y en el intento de legitimar el uso de la violencia, como mecanismo ineludible para imponerse a su adversario. Paradójicamente, son dos fuerzas que se oponen, pero que, al mismo tiempo, se necesitan mutuamente, ya que encuentran su principal vía de legitimación en la exigencia de fortalecerse para contrarrestar el poder de su oponente. En la práctica, ambas son negativas para el mundo islámico, ya que favorecen el mantenimiento de estructuras de poder que impiden el desarrollo de los necesarios procesos de emancipación y modernización que conduzcan hacia la democracia y la defensa de los derechos humanos.

\section{Nasr Hamid Abu Zayd (1943-2010)}

Nasr Hamid Abu Zayd nació, en 1943, en Tanta, localidad del delta de río Nilo, situada a unos ochenta kilómetros al norte de El Cairo. Estudió en la Facultad de Artes de la Universidad de El Cairo, graduándose en la especialidad de «Estudios Árabes», en 1972. Cinco años después, obtuvo la Licenciatura en «Estudios Árabes e Islámicos». Inició su ca- 
rrera docente como Instructor o Profesor Auxiliar en el Departamento de Lengua y Literatura Árabe, al mismo tiempo que enseñaba árabe para extranjeros en el Ministerio de Educación y en el Centro para Diplomáticos. En 1981 se doctoró en la especialidad de «Estudios Árabes e Islámicos», con una tesis sobre Ibn Arabí y, ya en 1987, comenzó a ejercer como Profesor Asistente en la Universidad de El Cairo. Tras una estancia de cuatro años como Profesor Visitante en la Universidad de Estudios Extranjeros de Osaka, regresa a El Cairo y, el 9 de mayo de 1992, presenta ante el Comité de Promoción Académica de esta Universidad su solicitud para acceder al cargo de Profesor, adjuntando, como parte de sus méritos investigadores, sus publicaciones realizadas hasta la fecha. Este trámite que Abu Zayd inició como un requisito meramente administrativo con la intención de continuar su carrera docente y académica, acabaría convirtiéndose en el hecho más determinante de su vida. El Comité de la Universidad remitió dicho material, para su evaluación, a un subcomité, formado por tres Profesores: el Dr. Abd al-Sabur Shahin, Profesor en el Colegio de Dar al-Ulum y predicador fundamentalista, el Dr. Mahmud Ali Makki y el Dr. Awni Abd alRa'uf'. El informe negativo del Dr. Shahin fue demoledor $y$, siete meses después, el Comité denegó la promoción, sin prestar atención a los informes favorables de los otros dos miembros del subcomité, así como a los escritos realizados por el Departamento de Estudios Árabes en los que se sostenía la calidad académica y docente, el mérito de sus contribuciones científicas, la originalidad de sus formas de razonamiento y la modernidad de los métodos científicos de investigación del postulante, Dr. Abu Zayd.

Shahin, además de Profesor en Dar alUlum, era un predicador habitual en las homilías de los viernes en la Mezquita Amr Ibn al-As de El Cairo. En su destructivo informe, además de intentar minimizar la importancia de las aportaciones de Abu Zayd, calificaba el conjunto de su obra investigadora como «terrorismo intelectual» 0 «SIDA cultural»y como «un intento marxista de destruir la sociedad musulmana egipcia» que no manifestaba sino una grave "atrofia de su conciencia religiosa» ${ }^{10}$. Desde el punto de vista argumental, reprendía a Abu Zayd por criticar a todos aquellos exégetas que habían mostrado una preferencia exclusiva por la tradición frente a la razón, así como por racionalizar la dominación de los Coraix (Quraysh) sobre el Islam y por afirmar que, en esencia, la historia islámica era el resultado de las conspiraciones iniciadas en los primeros tiempos por los califas de esta tribu. En relación con la fe islámica, lo acusaba de ridiculizar la creencia en lo sobrenatural que, en sus estudios, según Shahin, quedaba reducida a una mera invención fabulosa y mítica. Shahin consideraba que el análisis racional de los textos sagrados suponía atribuir una dimensión humana a la revelación y que este hecho no podía ser considerado sino como un auténtico insulto a la fe islámica.

Muy diverso fue el tono y el contenido del informe de otro de los miembros del subcomité, el Dr. Makki. Mahmud Ali Makki señala en su escrito la importancia de las investigaciones del Dr. Abu 
Zayd y, recogiendo una de las tesis principales del propio Abu Zayd, defiende que la comprensión racional y científica de la religión es un elemento esencial en todo intento de renacimiento cultural (nahda). Según Makki, las aportaciones del Dr. Abu Zayd mostraban un pensamiento moderno e ilustrado, basado en una consciente y competente lectura de la herencia islámica, en la que se combinaba una atinada erudición con un alto grado de habilidad analítica y deductiva. Esta capacidad para mezclar un profundo conocimiento de las fuentes literarias sagradas con el adecuado uso de las herramientas más avanzadas de los métodos lingüísticos y exegéticos contemporáneos permitía concebir la obra de Abu Zayd no como un atentado contra el Islam, sino como una de las más significativas fuerzas culturales activas, necesarias para el progreso de la nación egipcia ${ }^{11}$.

La denegación de la promoción provocó un duro enfrentamiento dialéctico entre fundamentalistas y progresistas en Egipto. Los pensadores progresistas afirmaban que la decisión del Comité manifestaba una clara derrota de la Universidad ante las presiones de las fuerzas fundamentalistas, como la Jama'a islámica o los azharíes, aun a costa de sacrificar la libertad e integridad académica, que había quedado sometida al informe de un predicador radical que practicaba el terrorismo dialéctico en nombre de la religión. Por el contrario, para los fundamentalistas, aquellos que se decían defensores de la libertad académica no eran sino un grupo de «izquierdosos», comunistas, ateos y seguidores del nasserismo ${ }^{12}$. En el fragor del conflicto dialéctico, el periódico Aqidati publicó una noticia en la que se afirmaba que un grupo de ulemas azharíes y, al menos, dos Profesores de la Universidad de El Cairo estaban iniciando acciones legales contra Abu Zayd para que fuera declarado apóstata, utilizando como argucia legal el concepto de hisba, doctrina de la jurisprudencia clásica islámica que teóricamente permite a cualquier musulmán personarse ante la justicia para denunciar a todo aquel que se considere que atenta contra la fe islámica ${ }^{13}$. Como confirmación de la noticia adelantada por Aqidati, el 10 de junio de 1993, un grupo de siete abogados, dirigido por Muhammad Samida Abd al Samad, presentaba la denuncia contra Abu Zayd ante el Departamento de Estatus Personal y Relaciones Domésticas del Tribunal de Primera Instancia de Giza, en la que se reclamaba que fuera declarado apóstata y que, en consecuencia, se produjera la disolución de su vínculo matrimonial con Ibtihal Yunis, ya que debía ser considerado como nulo el matrimonio realizado entre una creyente y un infiel. Los demandantes entregaron toda la documentación relativa al proceso de promoción docente de Abu Zayd, incluido por supuesto el informe del Dr. Shahin, como elemento principal de prueba sobre el que sustentar su petición. El 27 de enero de 1994, el Tribunal rechazó, en primera instancia, la acción por considerar que los demandantes no tenían la capacidad adecuada para iniciarla, pero, tras la apelación de los mismos, el 14 de junio de 1995, el Tribunal de Apelaciones revocó el faIlo inicial y sentenció que Abu Zayd era un apóstata y que, por lo tanto, su matrimonio debía ser disuelto. La defensa de 
Abu Zayd y el fiscal recurrieron el fallo pero, el 5 de agosto de 1996, el Tribunal de Casación, como tribunal egipcio civil supremo, ratificó la decisión de la Corte de Apelación ${ }^{14}$.

En paralelo al proceso judicial por apostasía, Abu Zayd había recurrido la decisión del Comité de Promoción de la Universidad quien, en último término, atendiendo a sus razonables argumentos, terminó por concederle el rango de Profesor, apenas unos días antes del fallo del Tribunal de Casación. Sin embargo, a pesar de que podía haber continuado su labor docente en Egipto, tras una breve estancia en Madrid, a donde había viajado junto a su esposa, ambos decidieron aceptar la plaza de Profesor Visitante que la Universidad de Leiden había ofrecido a Abu Zayd. En el año 2000, esta misma Universidad le concedió la Cátedra Honorífica Cleveringa en Leyes, Responsabilidad, Libertad de Culto y Conciencia y dos años más tarde, en el 2002, recibió, igualmente, la Cátedra Averroes de «Islam y Humanismo» de la vecina Universidad de Utrecht. No volvería a Egipto hasta el año 2010, justamente dos semanas antes de su muerte acaecida en el Cairo, el 5 de julio de 2010. Finalmente, tras el largo exilio, fue enterrado en su ciudad natal, Tanta.

La labor investigadora de Abu Zayd se inició con sendas obras en árabe dedicadas al estudio de los principios hermenéuticos de lectura del Corán en, por un lado, la escuela mutazilí y, por otro, la obra de Ibn Arabí, tituladas, respectivamente, El racionalismo en la exégesis. Estudio del problema de la metáfora en el Corán según los Mutazilíes (1982) y Filosofía de la hermenéutica.
Estudio de la hermenéutica del Corán en Ibn Arabí (1983). Posteriormente, también en lengua árabe, realizó una serie de escritos en los que analizaba cuestiones generales de lingüística, semiótica y hermenéutica en relación con las bases textuales del discurso religioso islámico, entre las que podemos citar, El concepto de texto. Estudio de las ciencias del Corán (1991), La cuestión de la lectura y los mecanismos de interpretación (1992) y Crítica del discurso religioso (1992). En su último grupo de obras en árabe Abu Zayd se ocupará, esencialmente, de reflexionar acerca de las profundas relaciones establecidas, en la historia del Islam, entre los mecanismos hermenéuticos de lectura del Corán y las estructuras jurídico-políticas dominantes en cada periodo histórico. Así, podemos observarlo en libros como El Texto, el Poder y la Verdad (1995) y El Califato y el poder de la Comunidad (1995). Escribió también textos críticos sobre la utilización interesada del discurso religioso islámico como herramienta de manipulación y sometimiento de la mujer, como Las mujeres en el discurso crítico (1994) y Los círculos del miedo. Análisis del discurso sobre la mujer (1999). Finalmente, en su exilio en los Países Bajos, escribió, en inglés, tres obras esenciales para comprender las claves del movimiento reformista islámico contemporáneo: Voice of an Exile. Reflections on Islam (2004), Rethinking the Qu'ran: Towards a Humanistic Hermeneutic (2004) y Reformation of Islamic Thought: a Critical Historical Analysis (2004).

En línea con el pensamiento de Arkoun, Abu Zayd sostiene que, en la historia del 
mundo islámico, la interpretación del Corán se fue, paulatinamente, convirtiendo en un duro campo de batalla en el que los diversos oponentes, apelando a la necesidad de proteger los auténticos principios islámicos extraídos de los textos sagrados, intentaban encubrir sus verdaderos objetivos de carácter esencialmente jurídico, político y económi$\mathrm{Co}^{15}$. Y, al igual que Arkoun, plantea que, en esta encarnizada e interesada pugna, desempeñó una labor esencial la determinación de los principios hermenéuticos de interpretación del Corán y la Sunna, en tanto que herramientas sustentadoras de los técnicas exegéticas esenciales sobre las que construir el basamento teórico de legitimación tanto de la sharía, como de los diversos sistemas políticos de raíz autoritaria que se fueron sucediendo a lo largo de la historia del Islam, a partir, sobre todo, de las prácticas jurídico-políticas de las grandes dinastías abasida y omeya.

Abu Zayd defiende que, en este proceso de control hermenéutico de las fuentes, destaca el papel desempeñado por dos principios exegéticos sustentados, supuestamente, en diversas aleyas del Corán: la doctrina de lo claro y de lo ambiguo, por un lado, y la teoría de la abrogación, por otro. En primer término, la doctrina de lo claro o irrevocable y de lo ambiguo o revocable defiende que, para interpretar los textos sagrados de forma correcta, hay que realizar una labor inicial que consiste en dividir sus aleyas en dos grandes grupos: las aleyas cuyo contenido sea considerado como claro, frente a aquellas cuyo mensaje sea entendido como ambiguo. Dilucida esta cuestión, se establece como máxima que todos aquellos principios que sean definidos como claros o irrevocables servirán para eliminar el contenido ambiguo de aquellos otros que, en consecuencia, serán considerados como revocables. Así pues, el establecimiento de las fuentes jurídico-políticas de la sociedades islámicas viene marcado por la tarea previa de determinar qué contenidos deben ser considerados como claros e irrevocables y cuáles, ambiguos y revocables. En segundo lugar, la teoría de la abrogación propugna un principio de derogación temporal, por el que se establece que el contenido último de la revelación deroga todos los contenidos anteriores que sean incompatibles con él. Al igual que sucedía con la doctrina de lo claro y de lo ambiguo, la aplicación de este principio hermenéutico exige una labor inicial de determinación, en este caso, del auténtico orden cronológico de la revelación sagrada. Para Abu Zayd, es evidente que las estructuras de poder imperantes en cada momento mostraban un inusitado empeño en controlar los procesos de decisión en estas dos tareas hermenéuticas determinantes, en la medida en que, de esta forma, reconducían toda la actividad exegética posterior hacia aquellas interpretaciones de los textos sagrados más acordes con la legitimación espuria de sus intereses.

Así, por ejemplo, en relación con la doctrina de lo claro y de lo ambiguo, tanto Abu Zayd como Arkoun señalan de qué forma, en lo que concierne a la posición de la mujer en las sociedades islámicas, las prácticas de selección y distinción entre lo claro y lo ambiguo fueron usadas, de manera manifiesta, con la fina- 
lidad evidente de legitimar la situación de sometimiento de la mujer. En el Corán se encuentran, por un lado, aleyas en las que se establece la igualdad absoluta del hombre y de la mujer ante Dios y, por otro, también aparecen versículos en los que se justifican ciertas diferencias en la situación social de ambos, en virtud de necesidades coyunturales, debidas, esencialmente, a exigencias específicas de la vida social como la distribución del trabajo o de las cargas familiares. Paradójicamente, en la práctica hermenéutica tradicional, las aleyas que establecían la igualdad, a pesar de contener un mensaje claro de igualdad ante Dios, fueron consideradas como ambiguas, frente a la supuesta claridad de las que propugnaban la desigualdad, por más que la mera lectura de las mismas muestre que las distinciones establecidas responden a necesidades sociales coyunturales muy condicionadas por las circunstancias históricas específicas de las comunidades islámicas medievales. En segundo lugar, el principio de abrogación fue utilizado para hacer prevalecer el denominado Mensaje de Medina, a costa de eliminar, casi por completo, el espíritu, por otra parte más original, del llamado Mensaje de la Meca. Abu Zayd cita, en este sentido, las ideas del pensador sudanés Mahmud Muhammad Taha, quien fuera ejecutado en 1985 tras ser condenado como apóstata y herético. Para Taha, el contenido de las revelaciones realizadas por el Profeta en la Meca, caracterizado por su defensa de la justicia, la libertad y la igualdad, fue totalmente eclipsado por el espíritu del mensaje de Medina, centrado en la ley, el orden y la obediencia. En su opinión, esa primacía otorgada al mensaje de Medina tenía sentido en las coordenadas históricas de las dinastías islámicas medievales imbuidas por un acendrado espíritu de disciplina interna, de combate y de conquista. Sin embargo, Taha sostiene que, en la actualidad, es necesario recuperar el sentido más original del mensaje del Profeta contenido en sus revelaciones de la Meca y reconstruir así una sharía más acorde con un sistema jurídico basado en la defensa de los derechos humanos ${ }^{16}$.

Al mismo tiempo, la utilización de la hermenéutica coránica, como principio de legitimación jurídico-política, se reforzaba con la teologización de las fuentes, por la que se extendía el carácter divino otorgado al Corán, no sólo a la Sunna, sino también a todas aquellas interpretaciones que se consideraran como auténticas, asegurando, de esta forma, el carácter eterno e inmutable de la sharía, en tanto que resultado último de la aplicación de los procedimientos exegéticos considerados como sagrados. Toda esta estructura hermenéutica de legitimación jurídico-política permitía crear la apariencia de que las sociedades islámicas se regían por un estricto sistema teocrático, cuyos mecanismos de creación normativa garantizaban a los fieles que el orden establecido era un fiel reflejo de la voluntad divina expresada en el Corán y no el producto del interés de las distintas dinastías califales por perpetuarse en el poder, mediante el blindaje religioso de sus arbitrarias e interesadas decisiones. En consecuencia, Abu Zayd coincide con Arkoun en defender la necesidad de desmontar este sistema espurio de utilización de los textos sagrados como mecanismo de legitimación jurídico-política. 
Apoyándose en la obra de Gadamer y Ricoeur, Abu Zayd sostiene que, para llevar a cabo esta necesaria labor de deconstrucción, es necesario aplicar una hermenéutica histórica, cuyos orígenes, en el seno del Islam, encuentra en la obra del filósofo andalusí Ibn Arabí y en la labor teórica de la escuela exegética medieval mutazili, ${ }_{17}^{17}$ a la que dedicó sus primeros escritos de reflexión sobre la hermenéutica coránica. Abu Zayd coincide con los mutazilies en su concepción del Corán como un texto de creación humana y, por tanto, como un producto cultural e histórico ${ }^{18}$. Frente al estatismo de las interpretaciones divinas del Corán, la concepción humana e histórica del mismo nos muestra su potencialidad hermenéutica como texto dinámico y vivo. Por esta razón, Abu Zayd prefiere considerarlo más que como un texto, como un discurso que, aunque posee una estructura fija, no agota en ella todo su contenido. De ahí que, desde un punto de vista semiológico, defienda que, aunque el sentido del Corán pueda ser considerado como algo estable, es indudable que su significado puede y debe variar, en virtud de las diversas circunstancias en que se desenvuelven los sujetos que se establecen como interlocutores del mismo en cada momento histórico. En su opinión, es indudable que la dimensión vertical sobre la que se sustentaba la supuesta trascendentalidad divina otorgada a los textos sagrados era, en realidad, una argucia con claras intenciones políticas, creada con la finalidad de conseguir que fueran justamente aquellos que delimitaban las formas de la verticalidad, esto es, de la relación de sumisión entre el creyente y la hermenéutica oficial de los textos sagrados, los que usaran la supuesta trascendencia hermenéutica como garantía del mantenimiento del sistema jurídico-político que mejor garantizaba sus intereses. Por esta razón, Abu Zayd apuesta por establecer una relación hermenéutica horizontal que facilite el diálogo directo de los sujetos con el texto. Esta horizontalidad hermenéutica facilitará el surgimiento de lecturas diversas que conviertan el Corán en un texto abierto, con capacidad para ofrecer opciones jurídico-políticas más acordes con las auténticas necesidades de las sociedades islámicas en las coordenadas históricas del mundo contemporáneo. Abu Zayd considera que esta concepción horizontal devolverá el carácter emancipador original del mensaje coránico, frente a los que, en su defensa del mantenimiento de la verticalidad, siguen apostando por el anacronismo de una supuesta lectura única que, en la práctica, inmoviliza la capacidad de acción de los pueblos islámicos. En palabras del propio Abu Zayd:

«Como conclusión podemos afirmar que defender que el conjunto de la literatura de la sharía es válido para cualquier comunidad musulmana, sin distinción de tiempo o lugar, es simplemente dotar de divinidad a las producciones históricas del pensamiento humano. En consecuencia, no hay obligación alguna de establecer un Estado teocrático denominado islámico. Tal exigencia no es sino una llamada ideológica para legitimar una autoridad teo-política de forma incuestionable. En otras palabras, supone el intento de reinstaurar un malévolo régimen dictatorial a expensas de la dimensión espiritual y ética del Islam». ${ }^{19}$ 


\section{Notas}

${ }^{1}$ ABU ZAYD, N.H., Reformation of Islamic Thought: A Critical Historical Analysis, Amsterdam, Amsterdam University Press, 2006, pp. 84-87 y CAMPANINI, M., II pensiero islamico contemporaneo, Bologna, II Mulino, 2009, pp. 112-117.

2 ABU ZAYD, N.H., op. cit., p. 84.

${ }^{3}$ ARKOUN, M., The Unthought in Contemporary Islamic Thought, London, Saqi Books, 2002.

${ }^{4}$ ARKOUN, M., Rethinking Islam: Common Question, Uncommon Answer, Boulder, Westview Press, 1994, p. 1.

${ }^{5}$ ARKOUN, M., La pensée arabe, Paris, P.U.F., 1979, p. 9.

6 Ibid., pp. 6-8.

${ }^{7}$ ARKOUN, M., «Lectures de la sourate 18», Annales. Histoire, Sciences Sociales, 35 année, n 3/4, mayo-agosto, 1980, p. 419.

8 Ibid., p. 37.

9 NAJJAR, F. M., "Islamic Fundamentalism and the Intellectuals: The Case of Nasr Hamid Abu Zayd», British Journal of Middle Eastern
Studies, vol. 27, n² 2, nov., 2000, pp. 177200.

10 Ibid., p. 179.

11 Ibid., p. 181.

12 Ibid., p. 182.

13 SFEIR, G. N., "Basic Freedoms in a Fractured Legal Culture: Egypt and the Case of Nasr Hamid Abu Zayd", Middle East Journal, vol. 52, nº. 3, Summer, 1998, pp. 402414.

14 BÄLZ, K., "Submitting Faith to Judicial Scrutiny through the Family Trial: The 'Abu Zayd Case'», Die Welt des Islams, New Series, vol. 37, issue 2, jul., 1997, pp. 135-155.

${ }^{15}$ ABU ZAYD, N.H., op.cit., p. 94.

16 Ibid., p. 88.

17 CAMPANINI, M., op. cit., pp. 94-95.

${ }^{18}$ ABU ZAYD, N.H. \& SEZGIN, H., El Corán y el futuro del Islam, Herder editorial, Barcelona, 2009, p. 9.

19 ABU ZAYD, N.H., Reformation of Islamic Thought, op .cit, p. 96. 